\title{
Clinical and Radiographic Characteristics of Upper Lumbar Disc Herniation: Ten-Year Microsurgical Experience
}

\author{
Motoyuki IWASAKI, ${ }^{1}$ Minoru AKINO, ${ }^{1}$ Kazutoshi HIDA, ${ }^{2}$ Shunsuke YANO, ${ }^{1}$ \\ Takeshi AOYAMA, ${ }^{2}$ Hisatoshi SAITO, ${ }^{1}$ and Yoshinobu IWASAKI ${ }^{1}$ \\ ${ }^{1}$ Sapporo Azabu Neurosurgical Hospital, Sapporo, Hokkaido; \\ ${ }^{2}$ Department of Neurosurgery, Hokkaido University Graduate School of \\ Medicine, Sapporo, Hokkaido
}

\begin{abstract}
Upper and lower lumbar disc herniation apparently have different background, symptoms, and operative results. This retrospective study reviewed the clinical records of 403 patients (409 discs) who underwent lumbar microdiscectomy performed by different surgeons at our institute between 1999 and 2009. The 290 male $(72.0 \%)$ and 113 female (28.0\%) patients were aged from 19 to 77 years (mean 44 years). Demographics, symptoms, and static and dynamic radiographic and magnetic resonance images obtained at the L1-2, L2-3, L3-4, L4-5, and L5-S1 intervertebral levels were analyzed. Of the 409 herniations, 3 were at L1-2, 9 at L2-3, 21 at L3-4, 166 at L4-5, and 210 at L5-S1. The mean age at herniation at L1-2 and L2-3 levels was 55.7 years. Patients with herniation of discs at L3-4 or above were significantly older than patients who suffered herniation at L4-5 or below ( $p<0.0001)$, and the incidence of urinary disturbance was significantly higher in patients with herniation at L1-2 and L2-3 levels $(p=0.0013)$. The incidence of degenerative scoliosis was significantly higher in patients with herniation at L1-2 and L2-3 than in those with herniated discs at L3-4 or below $(p<0.0001)$. Patients with upper lumbar disc herniation were older and manifested a higher incidence of urinary disturbance. A high incidence of degenerative scoliosis was noted in the course of prolonged degenerative processes.
\end{abstract}

Key words: upper lumbar disc herniation, urinary dysfunction, degenerative scoliosis, dorsal migration, microsurgery

\section{Introduction}

Lumbar discectomy was reported to be appropriate treatment in $80 \%$ of patients with lumbago and radicular pain in 1947.3) More recent studies have revealed differences in the symptoms, background, past medical history, and postoperative clinical course of patients with herniation at different lumbar disc levels. Patients with disc herniation at the L1-2 and L2-3 intervertebral levels had significantly higher incidence of prior lumbar surgery and additional arthrodesis compared to patients with herniation at L3-4. ${ }^{14)}$ On the other hand, patients with upper-level disc herniation did not show significantly different age, history of previous lumbar surgery, and postoperative outcomes based on the Oswestry Disability Index (ODI). ${ }^{13)}$ A randomized study of

Received December 14, 2010; Accepted March 8, 2011 lumbar disc herniation in the United States (Spine Patient Outcomes Research Trial ${ }^{10,11)}$ found that patients with upper-level disc herniation had better surgical prognosis.

The present retrospective study elucidated the clinical and radiographic characteristics of upper lumbar disc herniation to investigate the effect of the herniation level on treatment outcomes.

\section{Methods}

We created a database of 403 patients (409 discs) who had undergone lumbar discectomy at Azabu Neurosurgical Hospital between 1999 and 2009. All operations were performed with the operating microscope by various surgeons of our spinal team. The patients' medical records were retrospectively reviewed to record age, sex, past history of lumbar surgery, preoperative symptoms (back and radicular pain, motor and sensory disturbances, urinary dys- 
function, intermittent claudication, and Lasegue sign), and additional post-discectomy surgical interventions (reenucleation for disc recurrence, dural plasty for cerebrospinal fluid [CSF] leakage, abscess irrigation, and arthrodesis). Preoperative radiographic and magnetic resonance (MR) images were reviewed by one author (MI). The presence of degenerative scoliosis, spondylolisthesis, instability, and posterior epidural migration of disc fragments were included in the database. Degenerative scoliosis was recorded when the largest angle between the lines at the superior aspect of the upper lumbar vertebra and the inferior aspect of the lower vertebra on anteroposterior radiographic views (Cobb angle) exceeded $10^{\circ}$, instability when the posterior intervertebral opening angle on lateral radiographic view exceeded $10^{\circ}$ and hypermobility was present with the dynamic range of an intervertebral angle between flexion and extension greater than $10^{\circ}$, and posterior epidural migration of a disc fragment when there was a posterior projection over the posterior dural sac line drawn horizontally on $\mathrm{T}_{2}$ weighted axial MR images.

All patients underwent microdiscectomy using the Love method or laminectomy if there was evidence of central canal stenosis or apparent medialtype discs. Statistical analysis of data obtained at different disc levels was performed with two-way repeated measures analysis of variance $(\alpha=0.05)$ and pairwise multiple post hoc comparisons using the Bonferroni t-test ( $\alpha=0.0083$ ). The numbers of herniations at L1-2 and L2-3 were too small for statistical analysis, so were combined and evaluated as a group (L1-L3).

The medical records of most patients did not contain conventional pre- and postoperative evaluation data, as the different surgeons had graded back and radicular pain, and motor and sensory disturbance as improved, unchanged, or exacerbated. Therefore, our retrospective study replaced the recorded grade with continuous parameters and applied the paired t-test and intergroup comparison.

\section{Results}

Of the 409 discectomies, $3(0.7 \%)$ were at L1-2, $9(2 \%)$ at L2-3, $21(5 \%)$ at L3-4, $166(41 \%)$ at L4-5, and 210 $(51 \%)$ at L5-S1. The mean age of patients with herniations at the L1-L3 (mean \pm standard deviation, $55.7 \pm 14.4$ years) or L3-4 levels (59.9 \pm 14.2 years) was higher than in patients operated at L4-5 (41.8 \pm 14.8 years) or L5-S1 level (42.5 \pm 10.9 years) ( $p<$ $0.0001)$. The male:female ratio $(p=0.1048)$ and the incidence of prior lumbar surgery $(p=0.9940)$ were not statistically different irrespective of the level of herniation. Table 1 lists the incidence of preoperative symptoms, showing no significant difference in back and radicular pain, motor and sensory disturbances, intermittent claudication, and Lasegue sign between the different groups. On the other hand, significantly more patients with herniation at the L1-L3 levels manifested urinary dysfunction $(\mathrm{p}=$ 0.0013).

Comparison of the severity of pre- and postoperative symptoms, e.g. back and radicular pain, and motor and sensory disturbance, showed significant improvement irrespective of the operated level $(p<$ 0.05). Comparison of the symptom severity recorded before and 3 months after surgery found that more patients operated at L1-L3 tended to report persistent back pain $(\mathrm{p}=0.0609)$.

Of the 403 patients, 2 with discectomy at L3-4, 15 operated at L4-5, and 17 treated at L5-S1 required additional surgical intervention due to recurrent disc extrusion, CSF leakage, or wound infection; but were not statistically significant. None of the patients manifested symptomatic post-discectomy instability, so no arthrodesis procedures were performed in this series.

Posterior epidural migration of disc fragments occurred only in patients operated at L1-2 $(n=1)$ and L2-3 $(n=2)$; the overall rate in this series was $0.7 \%$. The incidence of degenerative scoliosis was significantly higher in patients operated at L1-L3 ( $\mathrm{n}=$ 6) than in the other groups (L3-4, $n=3 ; \mathrm{L} 4-5, \mathrm{n}=$ 24; L5-S1, $\mathrm{n}=11)(\mathrm{p}<0.0001)$. Half of patients with L1-L3 herniations had degenerative scoliosis. There

Table 1 Baseline symptoms categorized by herniation level

\begin{tabular}{|c|c|c|c|c|c|c|c|c|}
\hline Level & $\begin{array}{l}\text { No. of } \\
\text { discs }\end{array}$ & Back pain & $\begin{array}{l}\text { Radicular } \\
\text { pain }\end{array}$ & $\begin{array}{c}\text { Motor } \\
\text { disturbance }\end{array}$ & $\begin{array}{c}\text { Sensory } \\
\text { disturbance }\end{array}$ & $\begin{array}{l}\text { Intermittent } \\
\text { claudication }\end{array}$ & $\begin{array}{c}\text { Urinary } \\
\text { dysfunction }\end{array}$ & Lasegue sign \\
\hline L1-L3 & 12 & $9(75.0 \%)$ & 11 (91.7\%) & 5 (41.7\%) & 7 (58.3\%) & $4(33.3 \%)$ & $4(33.3 \%)$ & 7 (58.3\%) \\
\hline L3-4 & 21 & 18 (85.7\%) & $21(100 \%)$ & $7(33.3 \%)$ & 17 (81.0\%) & $6(28.6 \%)$ & $0(0 \%)$ & $14(66.7 \%)$ \\
\hline L4-5 & 166 & 149 (89.8\%) & $153(92.2 \%)$ & $47(28.3 \%)$ & $118(71.1 \%)$ & $13(7.8 \%)$ & $7(4.2 \%)$ & 122 (73.5\%) \\
\hline L5-S1 & 210 & 169 (80.5\%) & $202(96.2 \%)$ & $54(25.7 \%)$ & $155(73.8 \%)$ & $29(13.8 \%)$ & $14(6.7 \%)$ & $173(82.4 \%)$ \\
\hline Total & 409 & 345 (84.4\%) & 387 (94.6\%) & $113(27.6 \%)$ & $297(72.6 \%)$ & $52(12.7 \%)$ & 25 (6.1\%) & $316(77.3 \%)$ \\
\hline
\end{tabular}


was no statistically significant intergroup difference with respect to preexisting instability $(p=0.2580)$ and spondylolisthesis $(\mathrm{p}=0.8726)$.

\section{Discussion}

The concept of the "upper" lumbar discs has no clear definition of "upper," so many authors have classified lumbar levels from their own analysis data. ${ }^{2,10,13)}$ This study did not try to define the "upper" lumbar level, as all data were analyzed using intergroup comparison at the different disc levels. Consequently, this study did not detect any distinct "upper" level according to the difference of results from any examination. This study analyzed the clinical findings at each lumbar disc level based on a comparatively major series of Japanese patients.

Increasing age brings about changes in the mobility of various facets in the lower lumbar canal and mechanical stress shifts to the upper lumbar level. In fact, we also found that patients who underwent discectomy at L2-3 and L3-4 were significantly older than patients operated at L4-5 and L5-S1. ${ }^{10)}$ Significantly more patients operated at L1-L3 than L3-4 had undergone prior lumbar surgery and postdiscectomy arthrodesis. ${ }^{14)}$ Previous and the present findings suggest that age-related degeneration of the lumbar canal contributes to the occurrence of upper disc herniation. In our series, significantly more patients with herniation at L1-L3 presented with preoperative urinary disturbance, suggesting that morphological factors, such as smaller cross-sectional area of the upper compared to the lower lumbar canal, facilitate compression of the conus medullaris or multiple cauda equina. ${ }^{6}$

The postoperative outcomes recorded for our patient population suggest that discectomy at any of the studied levels yielded satisfactory results. Although pre- and postoperative data were not recorded based on conventionally-used parameters, most patients experienced symptom improvements. No difference was reported in the surgical outcome of patients operated at L3-4 or above and L4-5 or below, ${ }^{2)}$ and there was no statistically significant difference in the decrease in the ODI score in patients operated at L3-4 or above and L4-5 or below, although postoperative ODI scores were significantly higher in patients with upper lumbar disc herniation $(p=0.001){ }^{13)}$ Among our patients, those who had undergone surgery at L1-L3 tended to suffer persistent back pain, although an earlier randomized study ${ }^{10}$ ) found that at 2-year follow-up patients with upper lumbar herniations (L2-3 or L3-4) manifested significantly greater treatment effects than did patients with L5-S1 herniations for all outcome measures (Medical Outcomes Study Short Form-36 Health Survey [SF-36] bodily pain, physical functioning, and ODI). Differences in treatment effects between the upper lumbar levels and L4-5 were significant with respect to SF-36 bodily pain only; the greatest treatment benefits were obtained in patients with herniation at L2-3 and L3-4. On the other hand, in another randomized trial, ${ }^{1)}$ patients treated surgically for L4-5 herniation fared better than patients treated by discectomy at L5-S1. Studies using conventional evaluation parameters are underway at our institute to determine whether, and at what lumbar level, discectomy yields satisfactory treatment results.

Posterior epidural migration of disc fragment was only recognized at L1-2 and L2-3. Posterior migration is usually obstructed by the so-called "peridural membrane," which is the band medially attached to the lateral edge of posterior longitudinal ligament and extending to the lateral wall of spinal canal. ${ }^{15,16)}$ This peridural membrane limits the movement of the extruded disc fragment. ${ }^{7,15)}$ Other involved structures include the midline and lateral dural ligaments of Hoffmann, which connect the anterior dural surface to the posterior longitudinal ligament and posterior vertebral periosteum, ${ }^{17,18)}$ and normally lead to the lateral or posterolateral path of migration. ${ }^{12)}$ Traction, heavy labor, and hypermobility may predispose the disc to move posterior migration. ${ }^{8,9)}$ Review of this phenomenon found almost the same number of cases at all levels except for no cases at the L5-S1 level (L1-2 = 1, L2-3 = 4, L3-4 = 4 , and L4-5 = 5). Explanation of the basic distribution of cases at each disc level may involve frequent posterior epidural migration in the upper herniation group, which may be related to the vertebral rotation angle in the axial plane which tends to be wider at the upper lumbar vertebral level.

We found that upper lumbar disc herniation was associated with a high incidence of degenerative scoliosis. Although some studies documented disc degeneration at the concave aspect of scoliosis, 4,5$)$ we think that degenerative changes involving the disc and endplate can originate from preexisting scoliosis. Asymmetric degenerative disc changes and the subsequent development of frontal deviation and concomitant rotation with unilateral facet joints as a pivot produce what has been called the discogenic curve. ${ }^{1)}$ The development of the primary degenerative curve is primarily attributable to limited disc degeneration. Based on the chain of events in the course of the degenerative process, it is not surprising that the upper discs are primarily involved by degenerative scoliosis, and that mostly older individuals are affected. 


\section{References}

1) Aebi M: The adult scoliosis. Eur Spine J 14: 925-948, 2005

2) Aronson HA, Dunsmore RH: Herniated upper lumbar discs. J Bone Joint Surg Am 45-A: 311-317, 1963

3) Bradford FK, Spurling RG: The Intervertebral Disc with Special Reference to Rupture of the Annulus Fibrosus with Herniation of the Nucleus Pulposus, ed 2. Springfield, Illinois, Charles C Thomas, 1947, p 77

4) Buttermann GR, Mullin WJ: Pain and disability correlated with disc degeneration via magnetic resonance imaging in scoliosis patients. Eur Spine J 17: 240-249, 2008

5) Court C, Colliou OK, Chin JR, Liebenberg E, Bradford DS, Lotz JC: The effect of static in vivo bending on the murine intervertebral disc. Spine J 1: 239-245, 2001

6) Dora C, Walchi B, Elfering A, Gal I, Weishaupt D, Boos N: The significance of spinal canal dimensions in discriminating symptomatic from asymptomatic disc herniations. Eur Spine J 11: 575-581, 2002

7) Hogan $\mathrm{OH}$ : Lumbar epidural anatomy. A new look by cryomicrotome section. Anaesthesiology 75: 767-775, 1991

8) Kim JS, Lee SH, Arbatti NJ: Dorsal extradural lumbar disc herniation causing cauda equina syndrome: A case report and review of literature. J Korean Neurosurg Soc 47: 217-220, 2010

9) Kuzeyli K, Cakir E, Usul H, Baykal S, Yazar U, Karaarslan G, Arslan E, Peksoylu B: Posterior epidural migration of lumbar disc fragments: Report of three cases. Spine (Phila Pa 1976) 28: E64-67, 2003

10) Lurie JD, Faucett SC, Hanscom B, Tosteson TD, Ball PA, Abdu WA, Frymoyer JW, Weinstein JN: Lumbar discectomy outcomes vary by herniation level in the Spine Patient Outcomes Research Trial. J Bone Joint Surg Am 90: 1811-1819, 2008

11) Lurie JD, Tosteson ANA, Tosteson TD, Carragee E, Carrino J, Kaiser J, Sequeiros RT, Lecomte AR, Grove MR, Blood EA, Pearson LH, Herzog R, Weinstein JN:
Reliability of magnetic resonance imaging readings for lumbar disc herniation in the Spine Patient Outcomes Research Trial (SPORT). Spine (Phila Pa 1976) 33: 991-998, 2008

12) Robe P, Martin D, Lenelle J, Stevenaert A: Posterior epidural migration of sequestered lumbar disc fragments. Report of two cases. J Neurosurg 90(2 Suppl): 264-266, 1999

13) Saberi H, Isfahani AV: Higher Oswestry disability index is associated with better surgical outcome in upper lumbar disc herniations. Eur Spine J 17: 117-121, 2008

14) Sanderson SP, Houten J, Errico T, Forshaw D, Bauman J, Cooper PR: The unique characteristics of "upper" lumbar disc herniations. Neurosurgery 55: 385-389, 2004

15) Schellinger D, Manz HJ, Vidic B, Patronas NJ, Deveikis JP, Muraki AS: Disc fragment migration. Radiology 175: 831-836, 1990

16) Sen O, Aydin MV, Erdogan B, Yildirim T, Caner H: Cauda equina syndrome caused by posterior epidural migration of an extruded lumbar disc fragment. Turk Neurosurg 11: 108-110, 2001

17) Spencer DL: The anatomical basis of sciatica secondary to herniated lumbar disc: A review. Neurol Res 21 Suppl 1: S33-36, 1999

18) Wiltse LL, Fonseca AS, Amster J, Dimartino P, Ravessoud FA: Relationship of the dura, Hoffmann's ligaments, Batson's plexus, and a fibrovascular membrane lying on the posterior surface of the vertebral bodies and attaching to the deep layer of the posterior longitudinal ligament. An anatomical, radiologic, and clinical study. Spine (Phila Pa 1976) 18: 1030-1043, 1993

Address reprint requests to: Motoyuki Iwasaki, MD, Department of Neurosurgery, Hokkaido University Graduate School of Medicine, North 15 West 7, Kita-ku, Sapporo 060-8638, Japan. 